I N S T I T U T O

$\mathrm{DE}$

M E D I C I N A

T R O P I C A L

$\mathrm{DE}$

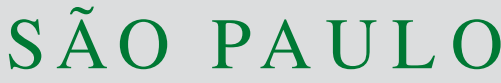

JOURNAL OF THE SÃO PAULO INSTITUTE OF TROPICAL MEDICINE

'University of Gujrat, Department of Biochemistry \& Biotechnology, Gujrat, Punjab, Pakistan

${ }^{2}$ The University of Haripur, Department of Medical Laboratory Technology, Haripur, Khyber Pakhtunkhwa, Pakistan

${ }^{3}$ Sandeman Provincial Hospital, Department of Surgery, Quetta, Balochistan, Pakistan

${ }^{4}$ National University of Medical Sciences, Department of Biological Sciences,

Rawalpindi, Pujab, Pakistan

${ }^{5}$ The University of Haripur, Department of Microbiology, Haripur, Khyber Pakhtunkhwa, Pakistan

Correspondence to: Aamer Ali Khattak The University of Haripur, Department of Medical Laboratory Technology, Hattar Road Near Swat Chowk, 22620, Haripur, Khyber Pakhtunkhwa, Pakistan

E-mail: amir.khattak@ hotmail.com

Nadia Zeeshan

University of Gujrat, Department of Biochemistry \& Biotechnology, Jalalpur Jattan Road, Punjab, 50700, Gujrat, Punjab, Pakistan

E-mail: nadia.zeeshan@uog.edu.pk hodbiochemistry@uog.edu.pk

Received: 30 April 2021

Accepted: 16 June 2021

\section{Surveillance of molecular markers of antimalarial drug resistance in Plasmodium falciparum and Plasmodium vivax in Federally Administered Tribal Area (FATA), Pakistan}

\author{
Muhammad Faisal Nadeem ${ }^{1}$, Aamer Ali Khattak ${ }^{(\mathbb{1} 2}$, Nadia Zeeshan', Hamza \\ Zahid $^{3}$, Usman Ayub Awan ${ }^{\circledR}$, Adnan Yaqoob ${ }^{1}$, Naeem Mahmood Ashraf', \\ Sana Gul ${ }^{4}$, Sadia Alam ${ }^{5}$, Waqas Ahmed 5
}

\section{ABSTRACT}

This molecular epidemiological study was designed to determine the antimalarial drug resistance pattern, and the genetic diversity of malaria isolates collected from a war-altered Federally Administered Tribal Area (FATA), in Pakistan. Clinical isolates were collected from Bajaur, Mohmand, Khyber, Orakzai and Kurram agencies of FATA region between May 2017 and May 2018, and they underwent DNA extraction and amplification. The investigation of gene polymorphisms in drug resistance genes (dhfr, dhps, crt, and $m d r l$ ) of Plasmodium falciparum and Plasmodium vivax was carried out by pyrosequencing and Sanger sequencing, respectively. Out of 679 PCR-confirmed malaria samples, $523(77 \%)$ were $P$. vivax, 121 (18\%) P. falciparum, and 35 (5\%) had mixed-species infections. All P. falciparum isolates had $p f d h f r$ double mutants $(\mathrm{C} 59 \mathrm{R}+\mathrm{S} 108 \mathrm{~N})$, while $p f d h f r / p f d h p s$ triple mutants $(\mathrm{C} 59 \mathrm{R}+\mathrm{S} 108 \mathrm{~N}+\mathrm{A} 437 \mathrm{G})$ were detected in $11.5 \%$ of the samples. About $97.4 \%$ of $P$. falciparum isolates contained pfcrt K76T mutation, while pfmdr1 N86Y and Y184F mutations were present in $18.2 \%$ and $10.2 \%$ of the samples. P. vivax pvdhfr S58R mutation was present in $24.9 \%$ of isolates and the $\mathrm{S} 117 \mathrm{~N}$ mutation in $36.2 \%$, while no mutation in the pvdhps gene was found. Pvmdrl F1076L mutation was found in nearly all samples, as it was observed in $98.9 \%$ of isolates. No significant anti-folate and chloroquine resistance was observed in $P$. vivax; however, mutations associated with antifolate-resistance were found, and the chloroquine-resistant gene has been observed in $100 \%$ of $P$. falciparum isolates. Chloroquine and sulphadoxine-pyrimethamine resistance were found to be high in $P$. falciparum and low in $P$. vivax. Chloroquine could still be used for $P$. vivax infection but need to be tested in vivo, whereas a replacement of the artemisinin combination therapy for $P$. falciparum appears to be justified.

KEYWORDS: Malaria. FATA. Plasmodium falciparum. Plasmodium vivax. Antimalarial drug resistance. Pakistan.

\section{INTRODUCTION}

Malaria is still a public health concern despite tremendous efforts to control and eradicate malaria. About 229 million malaria cases were reported by the World Health Organization (WHO) in 2020, with 0.41 million deaths globally ${ }^{1}$. About 205 million people in Pakistan live in the malaria-endemic areas, and 0.3 million confirmed cases are reported annually. According to the Malarial Control Program, Plasmodium vivax corresponds to $84 \%$ of all malarial infections, the proportion of Plasmodium falciparum is 15\%, and mixed-species infections are around $1 \%$ 
(P. falciparum and P. vivax). A Federally Administered Tribal Area (FATA) of Pakistan has the second-highest malaria incidence (23\%) in the country, after the Khyber Pakhtunkhwa (KPK) province $(31 \%)^{2}$. Political instability and war against terrorism during the last two decades have destroyed the health care system and its infrastructure in FATA. Other factors like militancy, Talibanization, Afghan refugees, migration of internally displaced people, and poor health system setup have ruined all efforts made by malaria control programs in this remote, neglected and malaria-endemic region ${ }^{3}$.

Chloroquine resistance (CQR) has first appeared in Thailand in 1957, then spread throughout South and Southeast Asia, eventually appearing in Sub-Saharan Africa and South America by the $1970 \mathrm{~s}^{4}$. CQR in P. falciparum was initially documented in Pakistan in the early 1980s, and according to a 1997 survey, CQR in the Pakistani population ranged from $18 \%$ to $62 \% 5$. According to a study conducted in Punjab province, 34\% of CQR was found in five districts ${ }^{6}$. In 2007, the national treatment guidelines for P. falciparum were released, contraindicating the use of CQ and encouraging the use of artemisinin with sulfadoxinepyrimethamine (SP). the artemisinin-based combination therapy (ACT) ${ }^{1}$. SP had been used as a monotherapy to treat malaria infections, and it had been also used as a partner drug to ACT before 2018. However, according to the WHO guidelines, artemether-lumefantrine plus primaquine is now the first-line treatment for uncomplicated confirmed P. falciparum malaria, while artesunate is indicated for the treatment of severe malaria in Pakistan ${ }^{1}$.

Single Nucleotide Polymorphisms (SNPs) in P. falciparum pfcrt and pfmdrl genes are well documented molecular markers related to the in vitro CQR. Polymorphism at codon K76T of the $p f c r t^{7}$ gene, and N86Y, Y184F, S1034C, N1042D and $\mathrm{D} 1246 \mathrm{Y}$ in the $p f m d r l$ gene confer $\mathrm{CQR}^{8}$. SP partner drug of ACT targets the P. falciparum folate metabolism pathway in which two enzymes act: dihydrofolate reductase (PDHFR) and dihydropteroate synthase (DHPS) ${ }^{9}$, that have been used as molecular related to the in vitro drug susceptibility ${ }^{10}$. In 2018, WHO recommended the replacement of the ACT partner drug from SP by lumefantrine due to the development of $P$. falciparum resistance to SP in Pakistan ${ }^{11}$. Polymorphism in the $p f d h d r$ gene at C50R, N51I, C59R, S108N, I164L codons as well as at S436A, A437G, K540E, A581G,A613T/S codons in pfdhps genes of P. falciparum have been associated with reduced SP susceptibility. Molecular markers of drug resistance against SP have been reported in a few studies on blood samples representing different Pakistan provinces except for the Federally Administered Tribal Area (FATA) in Pakistan ${ }^{12,13}$. In in vitro/in vivo investigations have revealed the artemisinin resistance along the Thailand-Cambodia border, in Vietnam, Myanmar and other Southeast Asian countries ${ }^{14}$ but it is still an effective antimalarial drug in Pakistan ${ }^{12,15}$.

In Southeast Asia, malaria due to $P$. vivax is prevalent, and $80 \%$ of the malaria burden come from India, Indonesiaand Pakistan ${ }^{1}$. The CQR mutation has been found in $100 \%$ of samples with $P$. falciparum; however, chloroquine plus primaquine is the first-line treatment for malaria due to P. vivax in Pakistan. SNPs in the pvmdrl gene have been associated with CQR in P. vivax, and two mutations at position Y976F and F1076L have been linked to chloroquine amodiaquine and 4-aminoquinolones resistance in $P$. vivax ${ }^{16}$. Resistance in $P$. vivax against SP has been associated with mutations in dihydrofolate reductase ( $p v d h f r)$ and dihydropteroate synthetase ( $p v d h p s$ ) genes. $P v d h f r$ mutations I13L, P33L, F57L/I, S58R, T61M, S117N/T, I173L/F, and pvdhps mutations $\mathrm{S} 382 \mathrm{~A} / \mathrm{C}, \mathrm{A} 383 \mathrm{G}, \mathrm{K} 512 \mathrm{M} / \mathrm{T} / \mathrm{E}$, and A553G/C genes have been linked to reduced susceptibility to pyrimethamine and sulfadoxine, respectively ${ }^{17}$.

In Pakistan, previous molecular antimalarial surveillance studies focused on different regions of Pakistan and FATA were neglected due to military operations and the war against terrorism. In this study, molecular markers associated with antimalarial drug resistance were investigated in $P$. falciparum and $P$. vivax clinical isolates collected from five FATA agencies/districts. Samples collected in 2017-2018 provided information regarding the prevalence of antimalarial resistant genotypes in the two predominant Plasmodium species: P. falciparum (pfdhfr, pfdhps, pfcrt, and pfmdrl) and $P$. vivax (pvdhfr, pvdhps and $p v m d r 1$ ). The study findings will contribute to a better understanding on the patterns of molecular drug resistance markers in P. falciparum/vivax in this region.

\section{MATERIALS AND METHODS}

\section{Study site and patient enrollment}

This study was carried out in the FATA agency, and in May 2018, this region was merged with the KPK province. FATA has unique geographical importance as it shares its border with Afghanistan to the West, KPK to the Northeast, and Balochistan to the South. It is located at latitude $34^{\circ} 28^{\prime} 24.59^{\prime \prime}$ North and Longitude $71^{\circ} 17^{\prime} 16.20^{\prime \prime}$ East, stretching for a maximum length of about 450 kilometers. Blood samples from malaria suspect cases were collected by the basic health units and different private health units from five agencies/districts (Bajaur, Mohmand, Khyber, Orakzai, and Kurram Agency) of FATA (Figure 1), KPK between May 2017 to May 2018. After explaining the study's purpose, informed verbal consent was taken from all patients or their 


\section{Federally Administered Tribal Areas (FATA), Pakistan}

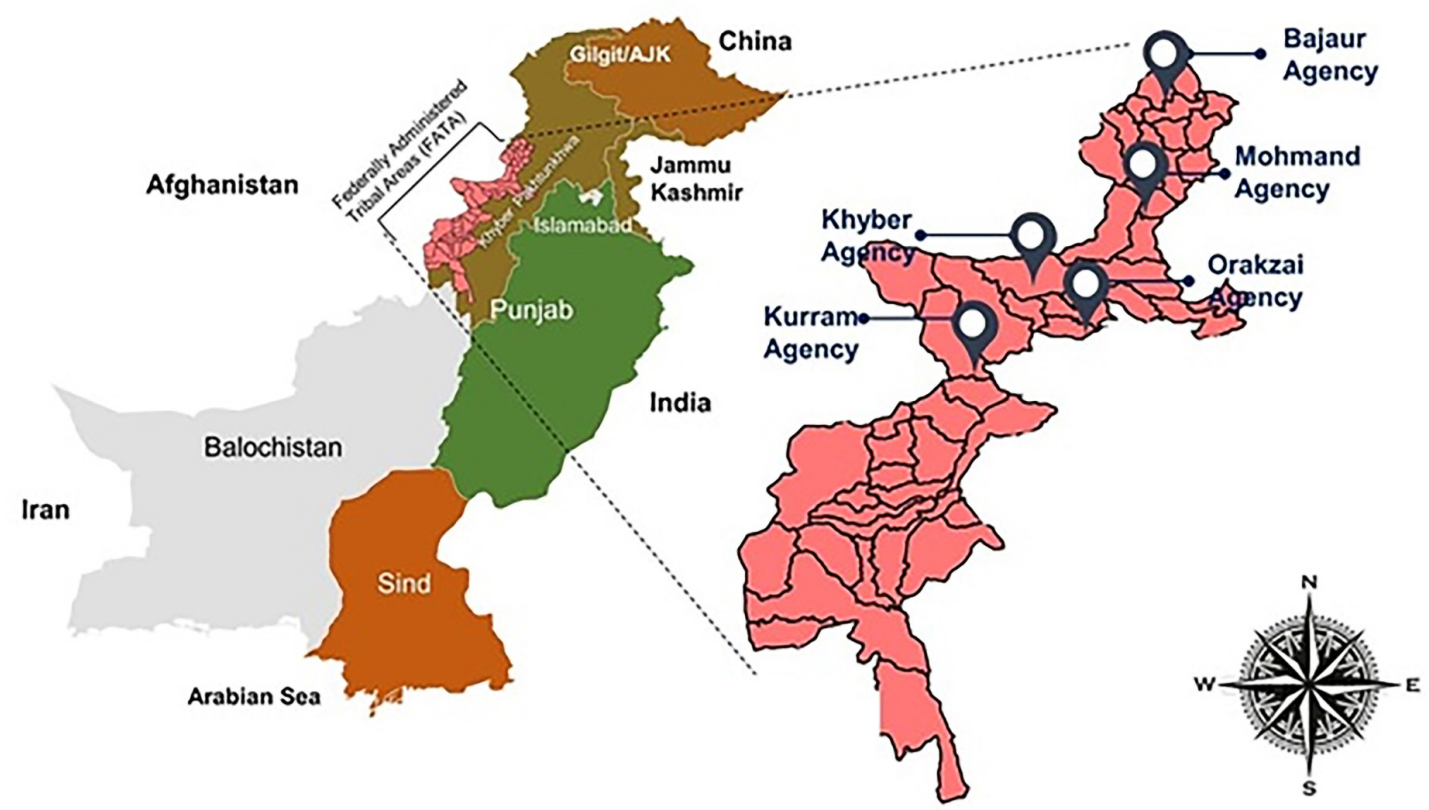

Figure 1 - Geographical map of Pakistan indicating the provinces and the FATA region.

legal guardians in the case of patients under the age of 18 The verbal consent was taken because it is a war-affected area, and the study population was mainly illiterate and the study would be of minimal risk to the study participants. All the questions raised by the participants were answered, and they were given time to decide if they wanted to participate. This consenting process was applied in the presence of an impartial witness. Ethical approval for this study was obtained from the ethical committee of the Department of Biochemistry \& Biotechnology, University of Gujrat, Gujrat, Punjab, Pakistan.

\section{Laboratory methodology}

A total of 762 malaria-positive blood samples, diagnosed by microscopy, were collected regardless of age and gender. About $3 \mathrm{~mL}$ of peripheral blood were drawn in EDTA tubes, and $50 \mu \mathrm{L}$ of whole blood were spotted on Whatman filter paper, dried, and stored at room temperature, and EDTA blood samples were stored at $-80{ }^{\circ} \mathrm{C}$. Malarial DNA was extracted from the dried blood spots using the QIAmp 96 DNA kit (Qiagen, Valencia, CA, USA) according to the manufacturer's instructions.

\section{Plasmodium DNA amplification by nested PCR}

Nested PCR was used to genotype the 18S rRNA Plasmodium gene with genus-specific and species-specific primers (P. falciparum, P. vivax, P. malariae and P. ovale) as previously described ${ }^{18}$. In addition, the PCR master mix, primer sequences, and thermal cycler conditions followed previously used protocols ${ }^{19}$. Nested PCR amplification products were electrophoresed on $2 \%$ agarose gels, along with a molecular ladder (Thermo Fisher Scientific, Waltham, MA, USA).

PCR amplification for pyrosequencing (pfdhfr, pfdhps, pfcrt, and pfmdr1)

Screening for polymorphism linked to anti-folate resistance, present at codons 50, 51, 59, 108164 of the pfdhfr gene and 436, 437, 540,581, 613 of the pfdhps gene in $P$. falciparum was performed by pyrosequencing using primers from a previously reported protocol ${ }^{20}$. The CQR molecular marker pfcrt codon K76T containing the gene fragment and N86Y and Y184F of the pfmdrl gene were amplified using the Khattak et al. ${ }^{11}$ protocol. PCR reagents and thermal cycler conditions were adopted from a previously described protocol with slight modifications. Briefly, in primary PCR reaction, $25 \mu \mathrm{L}$ reaction volume was used having $2 \mu \mathrm{L}$ of template DNA, 2x PCR buffer, $0.2 \mathrm{mM}$ dNTPs, $1.0 \mathrm{mM}$ magnesium chloride, $0.4 \mu \mathrm{M}$ primer (forward and reverse), and $0.04 \mathrm{U} / \mu \mathrm{L}$ Taq DNA polymerase (Promega, Madison, WI, USA). Then, about $2 \mu \mathrm{L}$ of the first PCR product were used as the template DNA for the nested PCR, $1 \times$ PCR buffer, $0.3 \mathrm{mM}$ dNTPs, 
$1.0 \mathrm{mM}$ magnesium chloride, $0.4 \mu \mathrm{M}$ both primers, and $0.04 \mathrm{U} / \mu \mathrm{L}$ Taq DNA polymerase, in a total volume of $50 \mu \mathrm{L}$. Primers and thermal cycler conditions followed previous protocols ${ }^{11,12}$. PCR was performed using a BioRad thermal cycler (Bio-Rad Laboratories, Hercules, CA, USA), and the amplification products were visualized on $2 \%$ ethidium bromide-stained agarose gels under UV lights. All samples were processed for pyrosequencing at the University of Maryland, School of Medicine facility in Baltimore, USA.

\section{Pyrosequencing reaction}

To investigate the mutations present at all codons of interest, pyrosequencing was carried on PyroMark $^{\circledR}$ Q96 MD Pyrosequencer (Qiagen, Valencia, CA, USA) using a published protocol ${ }^{20}$. Depending on the intensity/quantity of the amplification product, 3 to $6 \mu \mathrm{L}$ of the second PCR product or control samples (wild and mutant samples for each codon) were used in each pyrosequencing reaction. PyroMark $^{\circledR}$ software of Pyrosequencer Q96 MD version 1.2 Qiagen (Biotage AB, Uppsala, Sweden) was used to achieve an allele quantification mode (AQ) for all SNPs. However, pfcrt (codons 72-76) and pfmdrl (codons N86Y and Y184F) were analyzed using the sequence analysis mode (SQA). After adjusting each allele cut-off value against the control DNA using a standard curve, allele frequencies greater than $10 \%$ were considered.

Sequencing of $P$. vivax genes (pvdhps, pvdhfr, and pvmdr1)

A subset of 75 P. vivax samples from five FATA agencies/districts (study sites) were amplified targeting pvdhps (767 bp), pvdhfr (632 bp), and pvmdrl (547 bp) genes harboring mutations associated with CQR and SP resistance. Using previously described PCR master mix reagents protocols and cycling conditions, the first and second amplifications were carried out to amplify $p v d h p s$, $p v d h f r$, and $p v m d r l$ genes of $P$. vivax using blood samples and control samples (positive and negative) ${ }^{21}$. The first and second round PCRs master mix concentrations and thermal cycler conditions were the same for all three genes. Purified DNA samples were sent to the Sanger Sequencing Service at Macrogen Korea. All electropherograms were first visualized, then assembled, and finally analyzed by the Sequencher 4.1.10 (Gene Codes Corporation, Ann Arbor, MI, USA). Wild type genes $P$. vivax ARI/Pakistan isolated (GenBank accession N ${ }^{\circ}$ X98123), Sal-1 strain (GenBank accession no AY618622), and a Brazilian clinical isolate (GenBank accession $\mathrm{N}^{\circ}$ AY186730) were used for $p v d h f r$, pvdhps, and pvmdrl genes as reference sequences.

\section{RESULTS}

Out of 762 malaria- positive blood samples by microscopy, 679 samples were positive for Plasmodium DNA by PCR. From this total of samples, 523 (77\%) were positive for P. vivax, 121 (18\%) were positive for $P$. falciparum, and 35 (5\%) were found to harbor mixed infections. Among patients who tested positive for PCR, 468 (68\%) were male, and 211 (32\%) were female; the male to female ratio was 2.21. The patients' ages ranged from 6 months to 70 years, with a median of 22 years.

\section{Polymorphisms in pfdhfr, pfdhps, pfmdr1 and pfcrt genes of Plasmodium falciparum}

Pyrosequencing was used to detect SNPs in the $p f d h f r$, pfdhps, pfmdrl and pfcrt genes in 156 malaria-positive, PCR-confirmed isolates [121 P. falciparum mono-infections and 35 infections with mixed species ( $P$. falciparum plus $P$. vivax)]. All blood samples harbored C59R and S108N mutations; consequently, $p f d h f r$ double mutants $(\mathrm{C} 59 \mathrm{R}+\mathrm{S} 108 \mathrm{~N})$ were 156/156 (100\%), indicating a complete predominance of this haplotype in the study population. No mutation was observed at position I164L of the $p f d h f r$ gene. However, the double mutant C50R + N51I was found in 17/156 (10.9\%) of the isolates, and no triple pfdhfr (N51I + C59R + S108N) mutant was observed. In the pfdhps gene, S436A/F and A437G mutations were found in 16/156 (10.3\%) and 24/156 (15.1\%) of the isolates. All P. falciparum blood samples were wild-type at codon K540E, A581G and A613T/S. The prevalence of a combination of triple $d h f r / d h p s(\mathrm{C} 59 \mathrm{R}+\mathrm{S} 108 \mathrm{~N}+\mathrm{A} 437 \mathrm{G})$ mutant was 18/156(11.5\%) (Table 1). Pfmdrl polymorphism data showed that the frequency of N86Y and Y184F was $29 / 156(18.2 \%)$ and 16/156 (10.2\%), respectively. The

Table 1 - Frequency of genotype at various sites and SNPs in Plasmodium falciparum pfdhfr, pfdhps, pfmdr1 and pfcrt genes. Number of samples $=156$.

\begin{tabular}{lcc}
\hline Gene & Mutation/Haplotype & Samples No. (\%) \\
\hline pfdhfr & C59R & $156(100)$ \\
& S108N & $156(100)$ \\
& C50R+ N51I & $17(10.9)$ \\
pfdhps & C59R + S108N & $156(100)$ \\
& S436A/F & $15(10)$ \\
pfdhfr + pfdhps & A437G & $24(15)$ \\
pfmdr1 & N86Y $+437 G$ & $18(11.5)$ \\
& Y184F & $29(18.6)$ \\
pfcrt & K76T & $16(10.3)$ \\
\hline
\end{tabular}


Polymorphism analysis of the $p f c r t$ gene fragment showed 152/156 (97.4\%) K76T mutations.

\section{Polymorphisms in Plasmodium vivax pvdhfr, pvdhps and pvmdr1 genes}

Amplification and sequencing of the pvdhfr gene revealed that about $27 / 75$ (36.2\%) of $P$. vivax isolates harbored the $5117 \mathrm{~N}$ mutation while the incidence of the S58R single mutant was about 19/75 (25\%). A double pvdhfr $(\mathrm{S} 58 \mathrm{R}+\mathrm{S} 117 \mathrm{~N})$ mutant was observed in $17 / 71$ (23.9\%) of P. vivax blood samples (Table 2). Concerning the pvdhfr wild type gene sequence ( $P$. vivax ARI/Pakistan isolate GenBank accession no: X98123), the 18-bp double insertions (insertion I and II) and one 18 bp deletion were observed. Insertion I was located between the 91-92 codons, insertion II was between 102-104 codons, and deletions were between 92-97 codons after local alignment with the wild type $p v d h f r$ gene sequence. The tandem repeat region of the $P$. vivax $p v d h f r$ gene was aligned between amino acids 84 and 106 (Figure 2). Insertion II was the most common,

Table 2 - Frequency of genotype at various sites and SNPs in Plasmodium vivax pvdhfr, pvdhps and pvmdr1 genes. Number of samples $=75$.

\begin{tabular}{lcc}
\hline Gene & Haplotype & $\begin{array}{c}\text { No. samples and } \\
\text { (percentage) }\end{array}$ \\
\hline pvdhfr & IPFSTN I & $27(36)$ \\
pvdhps & IPFR TN I & $19(25.3)$ \\
& SAKAV (WT) & $73(97.3)$ \\
pvdhfr+pvdhps & SG KAV & $2(2.1)$ \\
& IPFSTSISAKAV (WT) & $29(38.7)$ \\
& IPFSTN ISAKAV & $26(35.5)$ \\
& IPFR TN ISAKAV & $17(23.8)$ \\
pvmdr1 & IPFSTN ISG KAV & $1(1.7)$ \\
& YF (WT) & $1(1.1)$ \\
\hline Pvdhfr & YL & $75(98.9)$ \\
\hline
\end{tabular}

Pvdhfr = wild type haplotype (IPFSTSI) I13L, P33L, F57L/I, S58R, T61M, S117N/T and I173L/F; Pvdhps = wild type haplotype (SAKAV) S382, A383, K512, A553 and V585; pvmdr1 = wild type haplotype (YF) Y976F and F1076L. accounting for $8 / 75$ (10.6\%), followed by deletions, which were observed in $5 / 75(6.6 \%)$ isolates, and insertion I was observed in $3 / 75(4 \%)$ isolates.

The majority of samples sequenced to investigate point mutations associated with the sulphadoxine resistant gene (pvdhps) were wild-type reference sequences (Brazilian clinical isolate accession no: AY186730). Only $2.1 \%$ of samples carrying the A383G mutation; however, none of the isolates presented with mutations at codon A553G in the pvdhps gene. The incidence of $p v d h f r+p v d h p s$ double mutants (S117N+A383G) was observed in $1.7 \%$ of specimens collected from the FATA region.

P. vivax CQR-associated mutations, Y976 and F1076, were screened after sequencing the $p v m d r l$ gene region between codons 931 and 1095 (Reference Sal-1 Gen-Bank accession $\mathrm{N}^{\circ}$ AY618622). The amplified gene fragments indicated $98.9 \%$ of mutations at codons F1076L and only $1.1 \%$ of samples harboring the Y976F mutation.

\section{DISCUSSION}

Malaria infection, the country's second most commonly reported disease, affects 205 million Pakistani. Molecular analysis of SP resistance-associated marker gene ( $p f d h f r$ ) in P. falciparum showed $100 \%$ prevalence of the double pfdhfr (C59R/S108N) mutant, indicating a complete predominance of this haplotype. Two previous studies from the FATA region reported $96 \%$ and $97.6 \%$ prevalence of the double $p f d h f r$ mutant ${ }^{12,22}$. In addition, a high incidence of the $p f d h f r$ double mutant has also been reported in different Pakistan cities $^{12,13}$.

In the present study, the $\mathrm{A} 437 \mathrm{G}$ mutation was observed in $15 \%$ of the isolates. Similar results were obtained when samples collected from the FATA Khyber Agency, reporting a $10.9 \%$ prevalence of the $\mathrm{A} 437 \mathrm{G}$ mutation ${ }^{12}$. In this study, $12 \%$ of P. falciparum isolates harbored $p f d h f r$ + pfdhps triple $(\mathrm{C} 59 \mathrm{R}+\mathrm{S} 108 \mathrm{~N}$ and $\mathrm{A} 437 \mathrm{G})$ mutation. A survey conducted in the FATA region has reported a 9.8\% prevalence of triple mutants, and it was comparatively lower than in the Balochistan province $(83.3 \%)^{12}$. A study published in 2013 reported a 51\% prevalence of pfdhfr+

\begin{tabular}{|c|c|c|c|c|c|c|c|c|c|c|c|c|c|c|c|c|c|c|c|c|c|c|}
\hline $\begin{array}{l}\text { Amino Acid } \\
\text { Position }\end{array}$ & 84 & & & & & & & & & & & & & 98 & & & & & 103 & & & 106 \\
\hline Insertion I & $\mathrm{S}$ & $\mathrm{Q}$ & $\mathrm{G}$ & G & $\mathrm{G}$ & $\mathrm{D}$ & $\mathrm{N}$ & $\mathrm{T}$ & $\mathrm{S}$ & G & $\mathrm{G}$ & $\mathrm{D}$ & $\mathrm{N}$ & $\mathrm{T}$ & $\mathrm{H}$ & $\mathrm{G}$ & $\mathrm{G}$ & $\mathrm{D}$ & $\mathrm{N}$ & $\mathrm{A}$ & $\mathrm{D}$ & $\mathrm{K}$ \\
\hline Insertion II & $\mathrm{S}$ & $\mathrm{Q}$ & $\mathrm{G}$ & $\mathrm{G}$ & $\mathrm{G}$ & $\mathrm{D}$ & $\mathrm{N}$ & $\mathrm{T}$ & $\mathrm{S}$ & G & $\mathrm{G}$ & $\mathrm{D}$ & $\mathrm{N}$ & $\mathrm{T}$ & $\mathrm{S}$ & $\mathrm{G}$ & $\mathrm{G}$ & $\mathrm{D}$ & $\mathrm{N}$ & $\mathrm{A}$ & $\mathrm{D}$ & K \\
\hline Deletion & $\mathrm{S}$ & Q & G & G & $\mathrm{G}$ & $\mathrm{D}$ & $\mathrm{N}$ & $\mathrm{T}$ & $\mathrm{S}$ & G & G & $\mathrm{D}$ & $\mathrm{N}$ & * & $*$ & $*$ & $*$ & $*$ & $*$ & $\mathrm{~A}$ & $\mathrm{D}$ & $\mathrm{K}$ \\
\hline
\end{tabular}

Figure 2 - Alignment of $P$. vivax pvdhfr gene sequences, focusing the tandem repeat region between amino acids 84 and 106 . The pink color indicates the tandem repeat, and the asterisk $\left(^{*}\right)$ in green colored boxes represent the tandem repeat deletion between positions 98 and 103. 
pfdhps triple mutation in all four Pakistan provinces, but samples from FATA were not included ${ }^{11}$. The decrease in the incidence of the $p f d h f r+p f d h p s$ triple mutant haplotype was also observed in Iran, decreasingfrom 53\% to $38 \%$ between 2008 and 2010 after exchanging CQ and $\mathrm{SP}$ monotherapy for $\mathrm{AS}+\mathrm{SP}^{23}$. No polymorphism was observed in pfdhps, codons K540E, A581G, and A613S/T while a study reported $4 \%$ and $3 \%$ of polymorphisms at K540E and A581G codons in Pakistan ${ }^{21}$. The highlyresistant quintuple mutant [combination of the $p f d h f r$ triple mutant $(51 \mathrm{I}+59 \mathrm{R}+108 \mathrm{~N})$ and the pfdhps double mutant $(437 \mathrm{G}+540 \mathrm{E})]$ associated with SP treatment failure ${ }^{24}$ was not reported in this study or in earlier reports from the FATA region in Pakistan ${ }^{12}$.

Analysis of mutations in the $p f m d r l$ gene showed that $18 \%$ of isolates had a mutation at codon N86Y, and $10 \%$ of isolates were mutated at codon Y184F; this findings contrasts with the ones from studies from Pakistan in which $25 \%$ of samples included mixed mutations (if both the wildtype and mutant alleles were detected) ${ }^{11}$. In Asia and Africa, the association of $\mathrm{CQR}$ with the N86Y codon mutation is not clear. There are still gaps to increase the understanding on the association of SNPs in pfmdrl gene with $\mathrm{CQR}^{25}$. Our results showed that $P$. falciparum CQ resistant K76T $p f c r t$ mutation has completely predominated or is near the $100 \%$ frequency as this mutation was observed in $97 \%$ of isolates collected by five FATA agencies. In 2009, a study of samples gathered from the Bannu area, which is near the FATA zone, found that $100 \%$ of samples had the pfcrt K76T mutation ${ }^{13}$. Similarly, a study conducted in Pakistan in 2013 found the same results ${ }^{8}$. A survey of clinical isolates collected from all over Pakistan in 2018 found that $98.3 \%$ of the country had the $\mathrm{CQR}^{15}$, and comparable results have been reported from adjacent countries ${ }^{26}$.

In $P$. vivax samples, the $\mathrm{S} 117 \mathrm{~N}$ (IPFSTNI single mutant) $p v d h f r$ haplotype was found in $36 \%$ of the samples in this study, and a survey from Pakistan in 2013 reported a $45 \%$ prevalence of this haplotype ${ }^{21}$. In contrast, another study from Bannu reported about $93 \%$ prevalence $^{13}$. Quadruple 57L/58R/61M/117T, triple 57L/58R/117 and double $p v d h f r$ $(57 \mathrm{~L} / 117 \mathrm{~N})$ mutant haplotypes have been associated with in vitro drug resistance ${ }^{16}$. This study found $p v d h f r$ double mutant S58R + S117N in $25 \%$ of clinical isolates reported from neighboring countries like India, Afghanistan and $\operatorname{Iran}^{27-29}$.

In this study, two insertions (I and II) and one deletion of 18 base pairs have been observed. These nucleotides insertion/deletion events in the $p v d h f r$ known repeated regions, as well as their roles, warrant more investigation. A study conducted in Southern Pakistan has also reported insertions/deletions in the $p v d h p s$ gene $^{30}$. Many studies have used these repeated regions to study $p v \mathrm{dhfr}$ and $p v \mathrm{dhps}$ alleles based on their genetic diversity ${ }^{31,32}$. An apparent association of tandem repeat variants with mutant alleles and disease severity has been proposed ${ }^{33}$. According to the studies, these tandem repeat variants could be employed in genotyping analyses of $d h f r$ and dhps alleles ${ }^{31,34}$.

$P$. vivax can be exposed to SP pressure (alone or in combination with artesunate) in an effect possibly involved in misdiagnosis, as mixed infections are frequently treated with SP or AS-SP.

Presumptive diagnosis is relatively high in Pakistan, especially in FATA where medical facilities are not adequate. However in some patients, $P$. vivax parasites are exposed to SP pressure at sub-therapeutic levels, which can favor the emergence of resistance to $\mathrm{SP}^{4}$. However, it seems that despite some use of SP or AS-SP, P. vivax isolates carrying the mutant $p v d h f r-p v d h p$ s have not been selected to a large extent.

The majority (97.9\%) of P. vivax isolates had the wild-type pvdhps haplotype (SAKAV), and only $2.1 \%$ of isolates had the mutant SGKAV haplotype; these findings are in line with a previous study ${ }^{21}$. The low prevalence of this pvdhps mutant haplotype SAKAV has been reported in Iran and Afghanistan ${ }^{35,36}$. The haplotype analysis revealed that IPFSTNI + SGKAV ( $p v d h f r+p v d h p s)$ mutations are rare in the FATA region as these mutations are significantly associated with extensive drug resistance revealed by the molecular marker. Our study found four mutations in pvdhps, namely F365L, M367L, D459Aand V498A, and out of these four mutations, two mutations, F365L, M367L, have been reportedin India ${ }^{33}$.

In the present study, only $1 \%$ of isolates had point mutation at codon Y976F, but $7 \%$ of mutations at this position Y976F have been reported in India ${ }^{37}$. Our findings are consistent with two other studies from neighboring countries that reported CQ susceptibility, but the mutant Y976F was not observed in these two studies ${ }^{38,39}$. The F1076L mutation in the $p v m d r 1$ gene of $P$. vivax isolates was highly predominant (99\%) in all FATA study sites which showas a nearly complete predominance. Our findings are in line with previous reports from Pakistan, in which about $98 \%$ of mutations have been reported at position F1076L. Nearly all isolates were wild-type at the Y796F position, suggesting that CQ resistance in $P$. vivax has not yet emerged, but many isolates carried the F1076L mutant ${ }^{13,21}$. Our study found the F1076L mutation in all samples compared to the reference wild type sequence, but few studies reported that this mutation alone could be non associated with CQ resistance.

In order to express CQR in P. vivax isolates, both mutations must be present, however there is no evidence 
that the Y976F mutation represents a molecular marker for CQ resistance ${ }^{40}$.

\section{CONCLUSION}

This is the first comprehensive report on molecular genotyping and molecular patterns of drug resistance markers in P. falciparum and P. vivax isolates in FATA regions of Pakistan. Drug resistance findings suggest that although there is a high prevalence of $p f d h f r$ double mutations in $P$. falciparum isolates across all FATA regions, these mutations are insufficient to transmit SP failure in clinical settings. In addition, a high prevalence of P. falciparum $\mathrm{CQR}$ markers has been found despite the discontinuation of drug pressure.

In $P$. vivax isolates, no primary chloroquine resistancemediating mutation was found; however, a continuous monitoring of pvmdrl mutations is essential to identify the emergence of CQ resistant $P$. vivax in the FATA regions. Furthermore, the utility of parasite molecular markers to monitor drug resistance significantly impacts malaria control and elimination in the war-torn malaria endemic area, FATA. Therefore, to better understand malaria transmission, continuous molecular studies to determine genetic diversity are recommended.

\section{ACKNOWLEDGMENTS}

We thank the study participants for their involvement in the study.

\section{AUTHORS' CONTRIBUTIONS}

MFN, AAK, NZ and AY conceived and designed thestudy, analyzed and interpreted the data. UAA, SG, NMA and MFN were involved in the statistical analysis, writing of the first draft of the manuscript and interpretation of results; MFN, SA, WA, HZ and AY performed the experimental procedures, acquisition of data and collection of samples. AAK, UAA and NZ performed the final correction of the manuscript. All authors approved the final version of the manuscript.

\section{CONFLICT OF INTEREST}

None to declare.

\section{REFERENCES}

1. World Health Organization. World malaria report 2020: 20 years of global progress \& challenges. Geneva: WHO; 2020. [cited 2021
Jun 16] Available from: https://www.who.int/publications/i/ item/9789240015791

2. Pakistan. Directorate of Malaria Control. Pakistan malaria annual report 2019. Islamabad: Directorate of Malaria Control; 2019. [cited 2021 Jun 16] Available from: http://dmc.gov. pk/documents/pdfs/Pakistan\%20Malaria\%20Annual\%20 Report\%202019\%20(002).pdf

3. Karim AM, Hussain I, Malik SK, Lee JH, Cho IH, Kim YB, et al. Epidemiology and clinical burden of malaria in the wartorn area, Orakzai Agency in Pakistan. PLoS Negl Trop Dis. 2016;10:e004399.

4. Hastings IM. The origins of antimalarial drug resistance. Trends Parasitol. 2004;20:512-8.

5. Shah I, Rowland M, Mehmood P, Mujahid C, Razique F, Hewitt $\mathrm{S}$, et al. Chloroquine resistance in Pakistan and the upsurge of falciparum malaria in Pakistani and Afghan refugee populations. Ann Trop Med Parasitol. 1997;91:591-602.

6. Rana MS, Tanveer A. Chloroquine resistance and Plasmodium falciparum in Punjab, Pakistan during 2000-2001. Southeast Asian J Trop Med Public Health. 2004;35:288-91.

7. Fidock DA, Nomura T, Talley AK, Cooper RA, Dzekunov SM, Ferdig MT, et al. Mutations in the P. falciparum digestive vacuole transmembrane protein PfCRT and evidence for their role in chloroquine resistance. Mol Cell. 2000;6:861-71.

8. Petersen I, Eastman R, Lanzer M. Drug-resistant malaria: molecular mechanisms and implications for public health. FEBS Lett. 2011;585:1551-62.

9. Nzila A. Inhibitors of de novo folate enzymes in Plasmodium falciparum. Drug Discov Today. 2006;11:939-44.

10. Saha P, Guha SK, Das S, Mullick S, Ganguly S, Biswas A, et al. Comparative efficacies of artemisinin combination therapies in Plasmodium falciparum malaria and polymorphism of pfATPase6, pfcrt, pfdhfr, and pfdhps genes in tea gardens of Jalpaiguri District, India. Antimicrob Agents Chemother. 2012;56:2511-7.

11. Khattak AA, Venkatesan M, Jacob CG, Artimovich EM, Nadeem $\mathrm{MF}$, Nighat F, et al. A comprehensive survey of polymorphisms conferring antimalarial resistance in Plasmodium falciparum across Pakistan. Malar J. 2013;12:300.

12. Yaqoob A, Khattak AA, Nadeem MF, Fatima H, Mbambo G, Ouattara A, et al. Prevalence of molecular markers of sulfadoxine-pyrimethamine and artemisinin resistance in Plasmodium falciparum from Pakistan. Malar J. 2018;17:471.

13. Khatoon L, Baliraine FN, Bonizzoni M, Malik SA, Yan G. Prevalence of antimalarial drug resistance mutations in Plasmodium vivax and P. falciparum from a malariaendemic area of Pakistan. Am J Trop Med Hyg. 2009;81: 525-8.

14. Ashley EA, Dhorda M, Fairhurst RM, Amaratunga C, Lim P, Suon S, et al. Spread of artemisinin resistance in Plasmodium falciparum malaria. New Engl J Med. 2014;371:411-23. 
15. Khan AQ, Pernaute-Lau L, Khattak AA, Luijcx S, Aydin-Schmidt B, Hussain M, et al. Surveillance of genetic markers associated with Plasmodium falciparum resistance to artemisininbased combination therapy in Pakistan, 2018-2019. Malar J. 2020;19:206

16. Marfurt J, de Monbrison F, Brega S, Barbollat L, Müller I, Sie A, et al. Molecular markers of in vivo Plasmodium vivax resistance to amodiaquine plus sulfadoxine-pyrimethamine: mutations in pvdhfr and pvmdr1. J Infect Dis. 2008;198:409-17.

17. Auliff A, Wilson DW, Russell B, Gao Q, Chen N, Le Ngoc A, et al. Amino acid mutations in Plasmodium vivax DHFR and DHPS from several geographical regions and susceptibility to anti-folate drugs. Am J Trop Med Hyg. 2006;75: 617-21.

18. Snounou G, Viriyakosol S, Jarra W, Thaithong S, Brown KN. Identification of the four human malaria parasite species in field samples by the polymerase chain reaction and detection of a high prevalence of mixed infections. Mol Biochem Parasitol. 1993;58:283-92.

19. Khattak AA, Venkatesan M, Nadeem MF, Satti HS, Yaqoob A, Strauss K, et al. Prevalence and distribution of human Plasmodium infection in Pakistan. Malar J. 2013;12:297.

20. Zhou Z, Poe AC, Limor J, Grady KK, Goldman I, McCollum AM, et al. Pyrosequencing, a high-throughput method for detecting single nucleotide polymorphisms in the dihydrofolate reductase and dihydropteroate synthetase genes of Plasmodium falciparum. J Clin Microbiol. 2006;44:3900-10.

21. Khattak AA, Venkatesan M, Khatoon L, Ouattara A, Kenefic LJ, Nadeem MF, et al. Prevalence and patterns of anti-folate and chloroquine drug resistance markers in Plasmodium vivax across Pakistan. Malar J. 2013;12:310.

22. Kakar Q, Sheikh S, Ahmed I, Khan MA, Jamil M, ElMohammady $\mathrm{H}$, et al. Efficacy of artemisinin-based combination therapies for the treatment of falciparum malaria in Pakistan (20072015): in vivo response and dhfr and dhps mutations. Acta TroP. 2016;164:17-22.

23. Afsharpad M, Zakeri S, Pirahmadi S, Djadid ND. Molecular monitoring of Plasmodium falciparum resistance to antimalarial drugs after adoption of sulfadoxine-pyrimethamine plus artesunate as the first line treatment in Iran. Acta TroP. 2012;121:13-8.

24. Grais RF, Laminou IM, Woi-Messe L, Makarimi R, Bouriema $\mathrm{SH}$, Langendorf $\mathrm{C}$, et al. Molecular markers of resistance to amodiaquine plus sulfadoxine-pyrimethamine in an area with seasonal malaria chemoprevention in south central Niger. Malar J. 2018;17:98.

25. Wurtz N, Fall B, Pascual A, Fall M, Baret E, Camara C, et al. Role of Pfmdr1 in in vitro Plasmodium falciparum susceptibility to chloroquine, quinine, monodesethylamodiaquine, mefloquine, lumefantrine, and dihydroartemisinin. Antimicrob Agents Chemother. 2014;58:7032-40.
26. Antony HA, Das S, Parija SC, Padhi S. Sequence analysis of pfcrt and pfmdr1 genes and its association with chloroquine resistance in Southeast Indian Plasmodium falciparum isolates. Genom Data. 2016;8:85-90.

27. Joy S, Ghosh SK, Achur RN, Gowda DC, Surolia N. Presence of novel triple mutations in the pvdhfr from Plasmodium vivax in Mangaluru city area in the southwestern coastal region of India. Malar J. 2018;17:167.

28. Rakmark K, Awab GR, Duanguppama J, Dondorp AM, Imwong M. Polymorphisms in Plasmodium vivax anti-folate resistance markers in Afghanistan between 2007 and 2017. Malar J. 2020;19:251.

29. Sharifi-Sarasiabi K, Haghighi A, Kazemi B, Taghipour N, Mojarad EN, Gachkar L. Molecular surveillance of Plasmodium vivax and Plasmodium falciparum DHFR mutations in isolates from southern Iran. Rev Inst Med Trop Sao Paulo. 2016;58:16.

30. Raza A, Ghanchi NK, Khan MS, Beg MA. Prevalence of drug resistance associated mutations in Plasmodium vivax against sulphadoxine-pyrimethamine in southern Pakistan. Malar J. 2013;12:261.

31. Alam MT, Bora H, Bharti PK, Saifi MA, Das MK, Dev V, et al. Similar trends of pyrimethamine resistance-associated mutations in Plasmodium vivax and P. falciparum. Antimicrob Agents Chemother. 2007;51:857-63.

32. Prajapati SK, Joshi H, Dev V, Dua VK. Molecular epidemiology of Plasmodium vivax anti-folate resistance in India. Malaria J. 2011;10:102.

33. Garg S, Saxena V, Lumb V, Pakalapati D, Boopathi P, Subudhi $\mathrm{AK}$, et al. Novel mutations in the anti-folate drug resistance marker genes among Plasmodium vivax isolates exhibiting severe manifestations. Exp Parasitol. 2012;132:410-6.

34. Prajapati SK, Joshi H, Valecha N. Plasmodium vivax merozoite surface protein-3 [alpha]: a high-resolution marker for genetic diversity studies. J Vector Borne Dis. 2010;47:85-90.

35. Leslie T, Mayan MI, Hasan MA, Safi MH, Klinkenberg E, Whitty $\mathrm{CJ}$, et al. Sulfadoxine-pyrimethamine, chlorproguanil-dapsone, or chloroquine for the treatment of Plasmodium vivax malaria in Afghanistan and Pakistan: a randomized controlled trial. JAMA. 2007;297:2201-9.

36. Awab GR, Pukrittayakamee S, Imwong M, Dondorp AM, Woodrow CJ, Lee SJ, et al. Dihydroartemisinin-piperaquine versus chloroquine to treat vivax malaria in Afghanistan: an open randomized, non-inferiority, trial. Malar J. 2010;9:105.

37. Joy S, Mukhi B, Ghosh SK, Achur RN, Gowda DC, Surolia N. Drug resistance genes: pvcrt-o and pvmdr-1 polymorphism in patients from malaria endemic South Western Coastal Region of India. Malar J. 2018;17:40.

38. Shalini S, Chaudhuri S, Sutton PL, Mishra N, Srivastava N, David JK, et al. Chloroquine efficacy studies confirm drug susceptibility of Plasmodium vivax in Chennai, India. Malar J. 2014;13:129. 
39. González-Cerón L, Montoya A, Corzo-Gómez JC, Cerritos R, Santillán F, Sandoval MA. Genetic diversity and natural selection of Plasmodium vivax multi-drug resistant gene (pvmdr1) in Mesoamerica. Malar J. 2017;16:261.
40. Tantiamornkul K, Pumpaibool T, Piriyapongsa J, Culleton R, Lek-Uthai U. The prevalence of molecular markers of drug resistance in Plasmodium vivax from the border regions of Thailand in 2008 and 2014. Int J Parasitol Drugs Drug Resist. 2018;8:229-37. 